\title{
CUSTOMER RELATIONSHIP MANAGEMENT CONCEPT IN THE ELECTRONIC BUSINESS ERA
}

\author{
Dejan STOJKOVIĆ ${ }^{1}$, Ratko ĐURIČIĆ ${ }^{2}$ \\ ${ }^{1}$ Railways of Republic of Srpska S.C. Doboj, 71, Svetog Save Street, Doboj, RS - Bosnia and Herzegovina. \\ Corresponding author. E-mail: magistardejo@gmail.com \\ ${ }^{2}$ Traffic faculty, Doboj, 52, Vojvode Misica Street, Doboj, RS - Bosnia and Herzegovina.
}

Accepted 5 November, 2011

\begin{abstract}
Electronic business (e-business, defined as business activities conducted over the Internet) has been one of the most remarkable information technology innovations in the last few decades (e-business era). With the involvement of the Internet in the Customer Relationship Management (CRM) concept, its functions have been changed a lot. The Internet enables ready identification of the customer/visitor, cost-efficient data collection, personalization, adaptation, and interactivity in the CRM process. Here comes electronic CRM (e-CRM). The purpose of this paper is to review that how customer relationships should be managed (CRM) in the age of the e-business.
\end{abstract}

Keywords: CRM concept, CRM process, e-CRM, Internet, e-business.

\section{INTRODUCTION}

The Internet brings with it ubiquitous connectivity, real-time access, and a simple universal interface provided by Web browsers. Traditional enterprises are transforming themselves into electronic business (e-businesses) by reinventing the way they carry out their business processes to take full advantage of the capabilities of the Internet. It is hard to recall any other innovation that has received as much press or as much hype. Electronic business (e-business, defined as business activities conducted over the Internet) has been one of the most remarkable information technology innovations in the last few decades (e-business era).

A new term for taking care of customers via the Internet, e-CRM, is recently applied by some organizational and academic communities (Ragins and Greco, 2003).

Judicious use of e-business impacts an institution's interaction with its customer interactions in a wide variety of areas (Foss and Stone, 2002):

- New distribution channels,

- New markets,

- New business models,

- Transparent marketplace,

- e-CRM,

- Reduced costs and improved service.
Internet and e-business are accountable for e in the e-CRM. It is essentially about conveying increased value to customers and to do business through digital channels. Dramatically all business are becoming a part of whole business. At present new things are possible which are in need of new technologies and skills (Friedlien, 2003). e-CRM is a new phenomenon that come out from the Internet and Web technology to facilitate the implementation of e-CRM. It focuses on internet- or web-based interaction between customer and service provider (Chang et al., 2005).

The convenience of shopping on-line may bring customers in through the virtual door, but what keeps them coming back through that same door is the overall quality of the customer experience. Webenabled organizations need to understand this, because the cost of marketing to an existing customer is $\$ 6.80$ over the Internet versus $\$ 34.00$ to attain a new web customer (Karpinski, 2001).

e-CRM within businesses has increased dramatically over the last few years, and will continue to do so in the future. There is a lack of literature on e-CRM and more research work is needed in this area (Lee et al., 2003). 


\section{APPROACHES TO CRM CONCEPT}

On the last decade all modern organisations take care about every of individual customers. Business practice proved that the customers are the biggest asset of a company, they are in permanent change, becoming more demanding, more profiled, more informed and usually precisely know their own needs and desires. Today, in the time of very developed flow of information, a customer is able to change company very easily. Due to all mentioned reasons, in 9th decade of the last century a special strategy had been developed, and was focused to the relationship of a company to its own customers. It was called Customer Relationship Management, or shortly CRM. It represents strategy that demands total devotion and acceptance of the concept from the management (Stojkovic, 2008).

CRM was born from relationship marketing and is simply the practical application of long standing relationship marketing principles which have existed since the dawn of business itself (Gummesson, 2004). However, a number of authors propose that an emphasis on the 4Ps marketing mix is no longer the dominant marketing logic and that relationship marketing may be a more appropriate "new" paradigm for marketing thought theory and practice (Dwyer et al., 1987). With increasing focus upon relationship marketing, the CRM linkage becomes clear: CRM provides management with the opportunity to implement relationship marketing on a company wide basis effectively. Shown in Figure 1., Customer Relationship Management is continuing process, based on iterative, cyclic realisation of four identical activities, where every new cycle represents annexing of previous one (Stojkovic, 2008). Possession of quality database about customers is in the base of the process, while information emerged from database analysis serves to the purpose of adaptation of the ways of achieving interaction with customers. Analysis of collected experiences is done at the end of the cycle in order to further adapt the activities.

CRM as cyclic process implies running of four activities: discovery of knowledge, planing of market, interaction with customer and refinement and analysis.

It is also recognized that CRM is a process, and as such can be understood either in terms of distinct phases of the relationships or in terms of the strategic phases that need to be undertaken to achieve relationship objectives. The process can be summarized to include four stages of the buyerseller relationship:

- identification of relationship partners,

- development of the relationship,

- maintenance of the relationship,

- re-evaluation of the relationship or its termination (Heide, 1994).

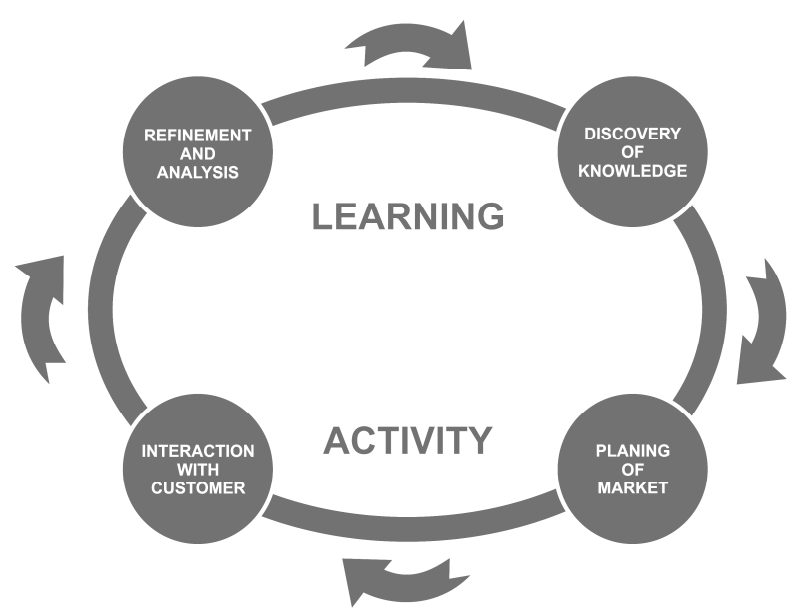

Figure 1: CRM as cyclic process (Stojkovic, 2008)

The strategic phases, on the other hand, may include:

- customer/segment identification,

- customer targeting,

- relationship marketing and management,

- the evaluation of the relationship and company performance.

Business-to-business (B2B) researchers prefer to understand CRM in terms of its process stages, while business-to-customer (B2C) researchers frequently conceptualize CRM in terms of its strategic activities. As such, the focus in B2B relationships appears to be centered around the development of long-term relationships through building trust and commitment among the exchange partners. On other hand, a central role is given to the development of loyal customers in B2C relationships. While the CRM priorities appear to be different in B2B versus B2C relationships, closer inspection would reveal that their aims are the same. Both attempt to create a small numbers situation between the company and the customer (or supplier) in otherwise competitive markets, and both seek enhanced profitability as the end-result of CRM activities.

\section{CRM CONCEPT AND E- BUSINESS AGE}

Electronic business (e-business, defined as business activities conducted over the Internet) has been one 
of the most remarkable information technology (IT) innovations in the last decade (Zhu et al., 2003).

E-business is using the network and distributed information technology, knowledge management, and trust mechanisms to transform key business processes and relationships with customers, employees, suppliers, business partners, regulatory parties, and communities (Craig and Jutla, 2000). Ebusiness is about changing business models to create new or increase value for the customer.

According to Vukmirovic (2004), e-business is business transformation based on: association of the companies (integration), cooperation process (collaboration) and global networking by using Internet as medium.

The emergence of the Internet heralded a new opportunity for customer relationship building (Croteau and Li, 2001). For one thing, search engines made it easier for customers to find online merchants and interact with them. Moreover, the Internet simplified bi-directional communication, for the first time offering a better way for consumers to relay personal information to the merchant. Instead of waiting to be mailed a form to open an account or order by phone, a prospective customer needed only to send an application through cyberspace, resulting in shorter delivery time, improved accuracy, and quite often a higher positive perception (Strauss and Hill, 2001). In fact, the Internet is an environment of zero latency, offering real-time information, and often on-demand product delivery (Bradshaw and Brash, 2001).

The Internet as a technological tool adds greater value to CRM, primarily through making the various stages/strategies of CRM more cost-efficient as well as enabling a host of other activities that would have otherwise been either impossible or arduous (Greenberg, 2002). The Internet enables ready identification of the customer/visitor, cost-efficient data collection, personalization, customization, and interactivity in the CRM process. These enhanced value-creating activities also expand the abilities of companies to establish, nurture, and sustain longterm customer relationships than ever before.

A new term for taking care of customers via the Internet, e-CRM, is recently applied by some organizational and academic communities (Ragins and Greco, 2003). e-CRM refers to electronic customer relationship management or, more simply, CRM that is Web-based (Dyché, 2001).
While traditional CRM activities remained distinct from web-enabled CRM, or e-CRM, in the early years of the "dot-com" era, it is being increasingly recognized that web-enabled CRM is now the norm rather than the exception (Greenberg, 2002).

Many authors agree that there is no unified definition of CRM / e-CRM. The term has been defined in different ways, with no clear agreement, but there are two approaches to define CRM / eCRM, management approach, and information technology approach. However, when we emphasis on management approach, some authors defined CRM stand for customer relationship management which is an integrated approach to identifying, acquiring and retaining customer (Ellatif, 2008).

Since the differences between CRM and e-CRM as mentions by many authors are minor and obvious, the definition for CRM and e-CRM is almost the same except e-CRM uses the Internet as a tool or medium. However, the definition of e-CRM is still not clear but most of the researchers and practitioners agree that e-CRM is a business strategy that applies the technology power to tie together all aspects of a company's business to build long-term customer relationship and customer loyalty.

According to Bradshaw and Brash (2001) to deal with the challenges of customer relationships in the fast-evolving Internet world, even the most customer-focused companies have to understand the three essential insights to getting customer relationships right:

1. That building CRM in the front office is just the start, and that it must involve the back office functions like manufacturing, fulfillment, and billing as well as the analytical functions like data warehousing and pushing customer insights back up to the front office.

2. That conducting relationships across multiple media requires the correct technical infrastructure, allowing companies to deal with their customers in a consistent way across multiple media, and even add new media as required without the need to develop every interface separately and from scratch.

3. Building the correct strategy for directing customers to different media. For a few organizations the strategy "we will deal with customers on whatever medium they prefer" is right; but for the vast majority of organizations it is a recipe for disaster.

Education and training of employees represents one of essential conditions for application of strategy of 
Customer Relationship Management in companies. According to Kotler, the symptom of insufficient orientation of a company toward customers is that there isn't training programme that would create customers culture (Stojkovic, 2010).

Training and preparation are arguably the most important key components in electronic Customer Relationship Management implementation. Depending on the number of users, training times will vary from company to company. Training of employees should occur before the new e-CRM system has been implemented to ensure a seamless transition for customers. Examples of training include sending users to training facilities at considerable cost or bringing in an on-site consultant. Anyone who requires access to the system should receive full, appropriate and timely training. Training should be an ongoing, managed activity as systems must continuously change and evolve. All training and tools used should be thoroughly documented for current, new and future employees. Without a documentation management scheme, the value of the e-CRM system will degrade rapidly. A firm should plan to spend about 5\% - 7\% of its total e-CRM implementation on training (Patton, 2001b).

Employees, i.e. is the persons that would use applied solutions of CRM concept in daily communication with customers, are extremely important segment. In the hands of quality educated and trained personnel, CRM starts to act as extremely powerful weapon and is able to allow decisive step toward gaining advantage over the competition (Stojkovic, 2010).

In a recent study (Sims, 2000), Anderson Consulting found that a typical $\$ 1$ billion high-tech company can gain as much as $\$ 130$ million in profits by improving its ability to manage customer relationships. Anderson Consulting also found that as much as $64 \%$ of the difference in return on sales between average and high performing companies is attributable to e-CRM performance. Such evidence indicates that the well-planned implementation of an e-CRM concept produces a winning situation for customers and companies alike. Improvements in the overall customer experience lead to greater customer satisfaction, which in turn has a positive effect on the company's profitability.

\section{E-CRM in Hewlett-Packard' s way}

Paul Horstmeier, newly appointed e-marketing manager of Hewlett-Packard, quickly discovered that the computer industry giant had made a muddle of its attempts at e-mail marketing (Patton, 2001a). The company's typical customers include IT managers who have purchased servers, printers and services before. HP had been launching separate, uncoordinated e-mail campaigns from nine different marketing groups. Horstmeier saw that in order to provide useful benefits to HP, his group needed to take over management of the e-mail campaigns from the nine different marketing groups. It also had to promote the idea that marketing should be a longterm process that focuses on the life cycle of customers instead of looking at a sale as a one shot transaction. This demanded that Horstmeier's group focus on the e-mail marketing operation while coordinating its efforts with the larger corporate structure that included other customerfacing groups like call centers and customer service teams. To meet these integration needs, the e-marketing group brought in e-mail analysis, segmentation and personalization tools from San Mateo, CA based Digital Impact. By analyzing its e-mail databases, HP found that its business customers fell into two groups; IT managers and end users. Rather than flooding the two segments with immediate additional e-mail campaigns, HP started to learn what these groups wanted through small pilot tests. The company found that IT managers were willing to tell HP exactly what kinds of general product support alerts and newsletters they'd like to get (such as laptop discussion forums, print driver updates, and new product introductions) whereas end users wanted more specific information about the exact product that they had bought (network server, PC or printer model number) and how to use it.

H.P.'s results showed that more of their customers responded to the low-cost email offer than to the direct mail offer, making the e-mail offer both more productive in terms of sales generated and more cost-effective in terms of expenses saved. Customers also said they liked getting the e-mail alerts and updates with more than $85 \%$ saying they were quite satisfied with the content that they received. The email campaigns generate an estimated $\$ 15$ million in new monthly sales revenues, as well as half a million dollars in monthly cost savings from the consolidated e-mail campaigns. By sending out product support alerts and e-mails, the resulting reduction in calls made to support lines saves nearly an additional $\$ 150,000$ per month (Patton, 2001a).

\section{CONCLUSIONS}

Electronic Customer Relationship Management (eCRM) has become the latest pattern in the domain of 
Customer Relationship Management. e-CRM concept is becoming more and more vital as businesses take to the e-business. All companies engaged in on-line relationships (B2B and/or B2C) need to educate themselves about the recent phenomenon of electronic Customer Relationship Management (e-CRM) concept. Training and preparation are arguably the most important key components in e-CRM implementation. Depending on the number of users, training times will vary from company to company. A firm should plan to spend about $5 \%-7 \%$ of its total e-CRM implementation on training (Patton, 2001b). Successful application of e-CRM concept produces a triumphant situation for customers and companies alike. By using e-CRM concept, improvements in the overall customer experience lead to greater customer satisfaction, which in turn has a positive effect on the company's quality and profitability. We have looked at the good practice of e-CRM at Hewlett-Packard.

\section{REFERENCES}

Bradshaw, D., \& Brash, C. (2001). Managing customer relationships in the e-business world: how to personalize computer relationships for increased profitability. International Journal of Retail \& Distribution Management, 29(12), 520-530.

Chang, T. M., Liao, L.L., \& Hsiao, W.F. (2005). An Empirical Study on the e-CRM Performance Influence Model for Service Sectors in Taiwan. Proceedings of IEEE International Conference on e-Technology, eCommerce and e-Service (EEE'05) (pp. 240-245). National Sun Yat-Sen University, Kaohsiung, Taiwan.

Craig, J., \& Jutla, D. (2000). e-Business Readiness: A Customer-Focused Framework (1st ed.). AddisonWesley Professional.

Croteau, A.M., \& Li, P. (2001). Critical Success Factors of CRM Technology Initiatives. Canadian Journal of Administrative Sciences, 1, 21-34.

Dwyer, F., Schurr, P., \& Sejo, O. (1987). Developing buyer-seller relationship. Journal of Marketing, 51(4), 11-27.

Dyché, J. (2001). The CRM Handbook: A Business Guide to Customer Relationship Management (1st Ed.). London, UK: Addison-Wesley Educational Publisher Inc.

Ellatif, M.M.A., (2008). A Cluster Technique to Evaluate Effect of ECRM on Customers' Satisfaction of ECommerce Websites.
Foss, B., \& Stone, M. (2002). CRM in Financial Services. London, UK: Kogan Page Limited.

Friedlein, A., (2003). Maintaining and Evolving Successful Commercial Web Sites Managing Change, Content, Customer Relationships, and Site Measurement. Elsevier Inc.

Greenberg, J. (2002). CRM at the Speed of Light: Capturing and Keeping Customers in Internet Real Time (2nd ed.). Berkeley, CA: McGraw-Hill/Osborne.

Gummesson, E. (2004). Return on relationships (ROR): The value of relationship marketing and CRM in business-to-business contexts. Journal of Business \& Industrial Marketing, 19(2), 136-148.

Heide, J. B. (1994). Interorganizational Governance in Marketing Channels. Journal of Marketing, 58(1), 7185.

Karpinski, R. (2001). To keep suppliers, e-marketplaces getting CRM-savvy. Retrieved from: www.btbonline.com

Lee, K.L., Gilbert, D, \& Mannicom, R. (2003). How eCRM can enhance customer loyalty? Marketing Intelligence \& Planning, 21(4/5), 239-248.

Patton, S. (2001a). The Truth About CRM. CIO Magazine, May 1.

Patton, S. (2001b). Talking to Richard Dalzell. CIO Magazine, September 15.

Ragins, E.D., \& Greco, A.J. (2003). Customer Relationship Management and E-Business: More Than a Software Solution. Review of Business, 1(1), 25-30.

Sims, D. (2000). A New ROI for New Economy CRM And Just Why Doesn't High-Tech Get It? retrieved from: www.crmguru.com

Stojkovic, D. (2008). Customer Relationship Management (CRM) - poslovna strategija, komponente, potrebe i proces. Tehnika, 4, 19-26.

Stojkovic, D. (2010). Aspekti koncepta upravljanja odnosima $\mathrm{s}$ potrošačima u poboljšanju kvaliteta usluga. Poslovna politika, 39(7/8), 59-63

Strauss, J. \& Hill, D.J. (2001). Consumer Complaints by E-Mail: An Exploratory Investigation of Corporate Responses and Customer Reactions. Journal of Interactive Marketing, 15(1), 63-73.

Vukmirovic, D. (2004). Internet marketing. School of organizational science Belgrade. Retrieved from: www.internet.fon.bg.ac.yu

Zhu, K., Xu, S., \& Dedrick, J. (2003). Assessing Drivers of E-business Value: Results of a Cross-Country Study. Proceedings of the Twenty-Fourth International Conference on Information Systems. 